Article

\title{
Effect on Silt Capillary Water Absorption upon Addition of Sodium Methyl Silicate (SMS) and Microscopic Mechanism Analysis
}

\author{
Qingwen Ma* and Sihan Liu \\ School of Water Conservancy Engineering, Zhengzhou University, Zhengzhou 450001, China; \\ m17839941418@163.com \\ * Correspondence: mqw2008@zzu.edu.cn
}

Received: 30 June 2020; Accepted: 22 July 2020; Published: 24 July 2020

check for updates

\begin{abstract}
Silt has the characteristics of developed capillary pores and strong water sensitivity, and capillary water is an important factor inducing the erosion and slumping of silt sites. Therefore, in order to suppress the effect of capillary water, this article discusses the improvement effect of sodium methyl silicate (SMS) on silt. The effect was investigated by capillary water rise testing and contact angle measurement, and the inhibition mechanism is discussed from the microscopic view by $\mathrm{X}$-ray diffraction $(\mathrm{XRD})$ testing, $\mathrm{X}$-ray fluorescence (XRF) testing, scanning electron microscope (SEM) testing and mercury intrusion porosimetry (MIP) testing. The results show that SMS can effectively inhibit the rise of capillary water in silt, the maximum height of capillary rise can be reduced to $0 \mathrm{~cm}$ when the ratio of SMS (g) to silt (g) increases to $0.5 \%$, and its contact angle is $120.2^{\circ}$. In addition, considering also the XRD, XRF, SEM and MIP test results, it is considered that SMS forms a water-repellent membrane by reacting with water and carbon dioxide, which evenly distribute on the surface of silt particles. The membrane reduces the surface energy and enhances the water repellence of silt, and combines with small particles in the soil, reduces the number of $2.5 \mu \mathrm{m}$ pores and inhibits the rise of capillary water.
\end{abstract}

Keywords: sodium methyl silicone; earth site; silt; the height of capillary rise; microscopic mechanism analysis; XRD; XRF; SEM; MIP

\section{Introduction}

Earth constructions are the remains of human history and culture in a certain environment, which is scientific, historic, artistic and non-renewable. However, a site with silty soil as the main material, because of its special grading characteristics, often has the characteristics of poor stability of the granular skeleton structure, developed capillary pores and strong water sensitivity, so the influence of capillary water on the silt buildings is particularly remarkable [1,2]. Usually, the height of capillary rise in the silt can reach $0.5-1.5 \mathrm{~m}$, or even more than $4 \mathrm{~m} \mathrm{[3-7].} \mathrm{The} \mathrm{moisture} \mathrm{content,} \mathrm{strength,} \mathrm{soluble} \mathrm{salt}$ content and microstructure of the soil under the long-term action of the capillary water are all seriously affected, which leads to a decrease in the structural stability and weakening of the foundation [8-11]. Therefore, it is necessary to study methods to control capillary rise in the silt sites.

In recent years, many researchers have improved silt by weakening the capillary rise of the silt. Raw materials such as glutinous rice flour, straw and tung oil were widely applied from the beginning of the Northern and Southern Dynasties (about 420 BC), which obviously changes the impermeability of a building, especially the impermeability of earthen buildings [12,13]; the conventional materials such as cement, fiber-cement, recycled bassanite and the like have also often been applied to improve the soil, and the improved silt is improved not only in strength, but also impermeability, and the rising 
height of capillary water is also decreased [14-16]. As a new type of material, high-molecular-weight polymer is also often applied to the modification of the silt, in which the detergents, polyalicyclic amine and simplot and the like have been proved to be effective [17-20]. However, earth constructions are not ordinary buildings-they are artistic, scientific, and historic, and cultural relics or cultural heritage is their primary attribute, so it is not suitable to apply the modified methods in the general construction process directly to the earth sites [21].

In order to suppress the capillary rise of the building body, many researchers have used some surfactants in building protection. Potassium methyl silicate showed obvious effects in the tests of inhibiting the hydration swelling and pulp making of mud shale. This prevented water from entering the shale by a hydrophobic membrane formed by organosilicate and the adsorption of potassium ions $[22,23]$. Sodium methyl silicate (SMS) also performed well in inhibiting the strength and water absorption of concrete. The test results showed that the microstructure of the sample with added sodium methyl silicate was more dense, and insoluble crystals in various shapes were inserted into the crack of concrete; this fully clogged the pores and cracks of the concrete, thus improving the macroscopic properties of concrete, including its waterproofing and impermeability [24-26]. Aiming to address the problem of high moisture absorption of microwave-hardened waterglass sand, some researchers have improved this moisture absorption by using sodium methyl silicate $[27,28]$. Sodium methyl silicate has also been applied to improve sand in yellow-flooding areas, and it was confirmed that the mechanical properties and the impermeability of the sand can be obviously improved by sodium methyl silicate, as shown by the compaction testing, the strength testing, and permeability testing [29].

Existing research verifies the good effect of SMS on inhibiting the water absorption of concrete, water glass, and other materials, and has a preliminary discussion about the mechanism. However, the use of SMS in the inhibition of capillary water in silt-based sites is rare, and study of the mechanism is insufficient. In order to verify the effect of SMS on capillary water absorption and provide a feasible method for the treatment of capillary water diseases, in this article we investigated the improvement effect of SMS on silt by a capillary water rise experiment and contact angle measurement, and we studied the inhibition mechanism by X-ray diffraction (XRD) testing, $X$-ray fluorescence (XRF) testing, scanning electron microscope (SEM) testing, and mercury intrusion porosimetry (MIP) testing.

\section{Materials and Methods}

\subsection{Materials and Sample Preparation}

Zhengzhou Shang city is the ruins of the capital city the Shang Dynasty (about 1600 BC-1046 BC), located in Guancheng District, Zhengzhou, China. Zhengzhou Shang city is 25 square kilometers and is the largest capital city ruins after the Yin Ruins in the Shang Dynasty. It is of great value for studying the history of the Shang Dynasty and the history of ancient city development. The materials used in the tests were taken from the site of Zhengzhou Shang city, and the soil samples were taken as brownish-yellow silt between 0 and $20 \mathrm{~cm}$ from the surface of the ground. Soil samples were taken to the laboratory, and their physical properties were analyzed according to the Highway Geotechnical Test Code (JTG E40-2007) [30]. The results are shown in Table 1. After removing the obvious debris from the soil, the soil was ground and passed through a $2 \mathrm{~mm}$ sieve; then we took the required amount of soil samples after screening and dried them in an oven at $105^{\circ} \mathrm{C}$ for $12 \mathrm{~h}$ to make pretreated dry silt.

Table 1. Basic physical properties of the soil samples.

\begin{tabular}{ccccccc}
\hline Soil Type & Density/g $\cdot \mathbf{c m}^{-3}$ & $\begin{array}{c}\text { Initial Moisture } \\
\text { Content/\% }\end{array}$ & Porosity/\% & $\begin{array}{c}\text { Liquid } \\
\text { Limit/\% }\end{array}$ & $\begin{array}{c}\text { Plastic } \\
\text { Limit/\% }\end{array}$ & $\begin{array}{c}\text { Plasticity } \\
\text { Index }\end{array}$ \\
\hline Silt & 1.7 & 6.8 & 33.8 & 23.4 & 18.1 & 8.9 \\
\hline
\end{tabular}

According to the test results based on previous preliminary tests and references, the proportions of SMS (g)/dry silt (g) were initially selected as $0 \%, 0.15 \%, 0.2 \%, 0.3 \%, 0.4 \%$, and $0.5 \%$, and we numbered 
them sequentially as Sample 0, Sample 1, Sample 2, Sample 3, Sample 4, Sample 5 [22,23,29]. In order to avoid affecting the test results due to different moisture content, the moisture contents of all samples were controlled at $10 \%$, that is, each sample contained $2 \mathrm{~kg}$ of dry silt and $0.05 \mathrm{~kg}$ of water.

Taking the preparation of Sample 1 as an example, the preparation process can be summarized as follows: first, weigh $2 \mathrm{~kg}$ of dry soil, $0.05 \mathrm{~kg}$ of water and $3 \mathrm{~g}$ of SMS into different containers; secondly, add $0.05 \mathrm{~kg}$ of water to the SMS container in small quantities many times, and slowly stir the samples using a glass rod; finally, slowly add the SMS solution to the dry soil, stir the soil thoroughly and place it in a sealed bag for $12 \mathrm{~h}$, so that the solution is evenly distributed throughout the soil. The layered compaction method was used to pour into the capillary water pipe for sample preparation.

\subsection{Capillary Water Rise Testing}

In order to study the effectiveness of SMS in inhibiting silt capillary water absorption, the above six soil samples were subjected to capillary water rise testing in turn. The specific test equipment and test steps were in accordance with the "Highway Geotechnical Test Code" JTGE40-2007 [30], and we measured the capillary water rising height after the opening of the lock until the rise was stable. Because the maximum height of the test tube was $100 \mathrm{~cm}$, measurements were stopped when they reached $100 \mathrm{~cm}$.

\subsection{Contact Angle Measurement}

The contact angle is the angle, conventionally measured through the liquid, where a liquid-vapor interface meets a solid surface, and it is written as $\omega$. This value can accurately quantify the degree of soil surface wetting. We observed the water repellency by dropping water first, then used a contact angle instrument to measure the contact angle.

\subsection{X-ray Diffraction (XRD) and X-ray Fluorescence (XRF) Testing}

XRD (D8 ADVANCE, Brooke, Germany) can determine the main phase of the sample, and XRF can determine the constituent elements of the sample. By combining the results of XRD and XRF, the composition and elements of soil before and after adding SMS can be discussed.

\subsection{Scanning Electron Microscopy (SEM) Testing}

The principle of a scanning electron microscope (SEM) (Quanta 650, Portland, OR, USA) is to scan a sample with a high-energy electron beam to produce a variety of physical information. By receiving, magnifying and displaying this information, the contact relationship between particles and pores can be reflected directly [31,32]. In order to study the improvement mechanism of SMS from the perspective of microstructure and morphology, it was necessary to observe the microstructure of soil samples before and after adding SMS solution.

\subsection{Mercury Intrusion Porosimetry (MIP) Testing}

MIP testing can measure the pore size from hundreds of microns to several nanometers, and the equivalent volume of pores can be evaluated by measuring the quantity of mercury entering pores under different external pressure, which can accurately quantify the internal pore morphology of porous materials. MIP has been widely used in different fields [33]. We used MIP in order to better study the mechanism by which methyl sodium silicate inhibits silt capillary water absorption, especially the optimization of the pore distribution.

\section{Results and Discussion}

\subsection{Observations on the Speed of Soil Capillary Water Absorption}

The capillary water rising trends of the six soil samples over time are shown in Figure 1. As can be seen from the figure, as time went by, the rising trends of capillary water in the six soil samples 
were roughly the same. Within the first $8 \mathrm{~h}$ of the rise of capillary water, the increasing speed was the fastest in unit time, and then became flat gradually. Sample 0 had the fastest rising speed and took 10 days to reach the maximum rise height. Figure 1 shows that Sample 0 rose rapidly to $100 \mathrm{~cm}$ within $120 \mathrm{~h}$, while capillary water in Sample 1 tended to rise steadily and slowly after $48 \mathrm{~h}$ until reaching the highest height of $70 \mathrm{~cm}$; Sample 2 tended to rise slowly after $48 \mathrm{~h}$ and became stable at about $35 \mathrm{~cm}$; the capillary water in Samples 3 and 4 rose slowly to maximum height and remained stable within $24 \mathrm{~h}$; Sample 5 did not even show any rise of capillary water.

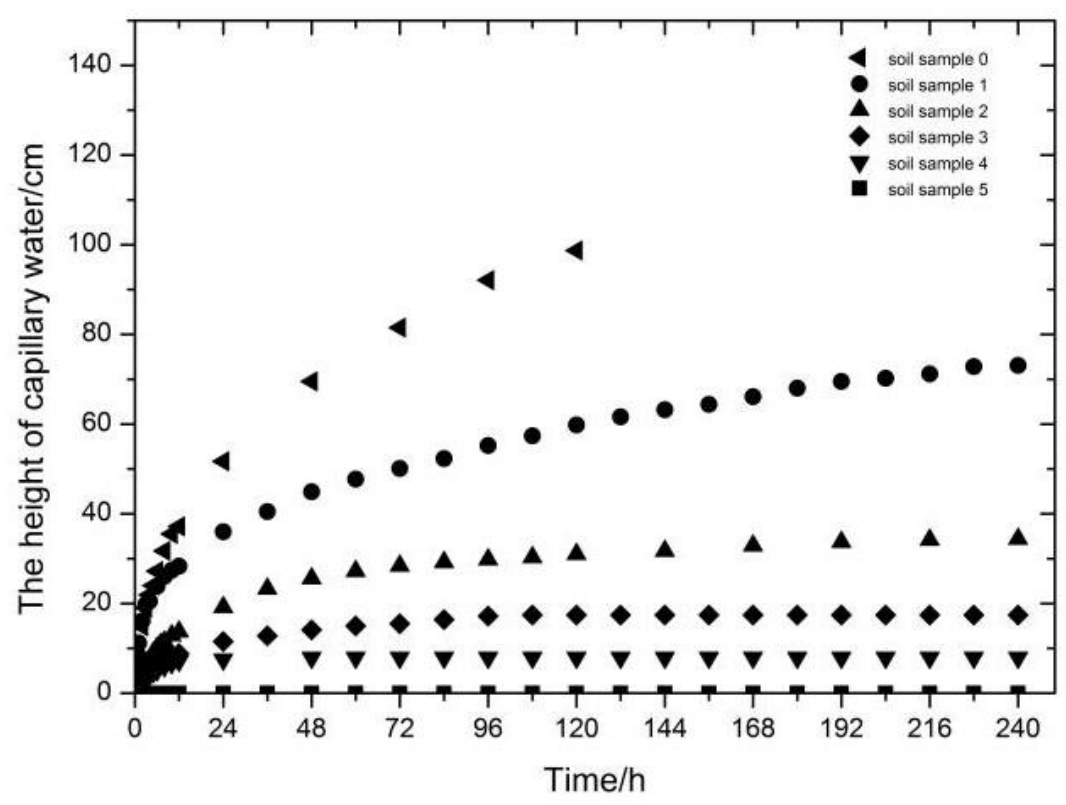

Figure 1. The relationship of the rise height of capillary water with time.

The six test results show that the capillary water rises rapidly in the original soil sample and the rising height can reach more than one meter because of the inferior silt, while the addition of SMS effectively weakens the rise of capillary water in soil. When the ratio of SMS (g) to dry silty soil (g) increases to $0.5 \%$, the capillary rise phenomenon no longer occurs in the test tube.

\subsection{Contact Angle Measurement and Analysis}

Figure 2 shows the different water droplet forms on the surface of different soil samples. Figure 3 shows contact angle images of Sample 5. As shown in Figure 2, when the droplets were dropped on the surface of the Sample 0, the droplets immediately infiltrated into the soil, and the contact angle was recorded as $0^{\circ}$. Meanwhile the water droplets dropped on the Sample 5 formed an obvious ellipsoid shape, and the contact angle was $120.2^{\circ}$. A material is generally considered to be hydrophobic when the contact angle $\omega$ is greater than $90^{\circ}$.

According to the physical and chemical theory of the surface, when the liquid comes into contact with the solid, the liquid will tend to spread. For the liquid phase, there are two main forces: cohesion and adhesion. Cohesion $W_{c}$ is the attraction between each part of the water molecules, while adhesion $W_{a}$ is the attraction between the liquid- and solid-phase molecules. The formulas of cohesion and adhesion are Equations (1) and (2), respectively.

$$
\begin{gathered}
W_{c}=2 \sigma_{L G} \\
W_{a}=\sigma_{L G}+\sigma_{S G}-\sigma_{S L}
\end{gathered}
$$

Here, $\sigma_{L G}$ is the liquid-gas interface attraction; $\sigma_{S L}$ is the liquid-solid interface attraction; $\sigma_{S G}$ is the solid-gas interface attraction. 
The expression of Gibbs surface free energy is shown in Equation (3).

$$
\Delta G / A_{S}=\sigma_{S L}+\sigma_{L G}-\sigma_{S G}
$$

We can substitute Formulas (1) and (2) into Formula (3) to obtain Formula (4).

$$
\Delta G / A_{S}=W_{a}-W_{c}
$$

According to the second law of thermodynamics, when the reaction is a spontaneous process, we have $\Delta G<0$. That is, when the cohesion is less than the adhesion, the water will spread and deepen on the surface of the material; when the adhesion is less than the cohesion, water will self-gather on the surface of the material, forming an ellipsoid shape as shown in Figure 2.

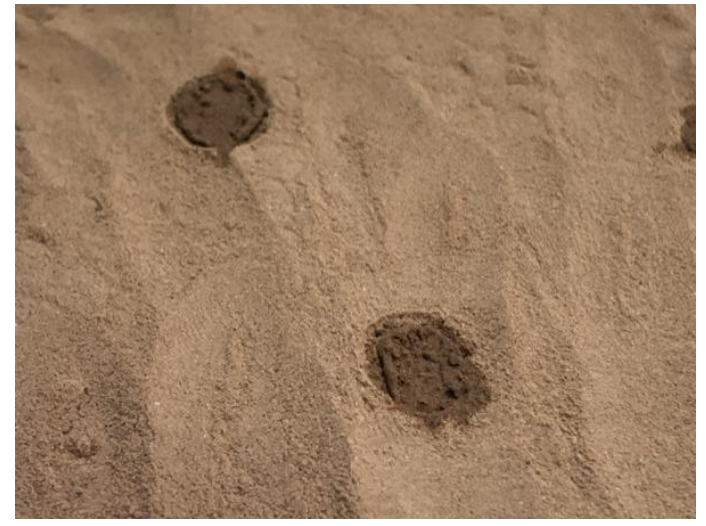

(a)

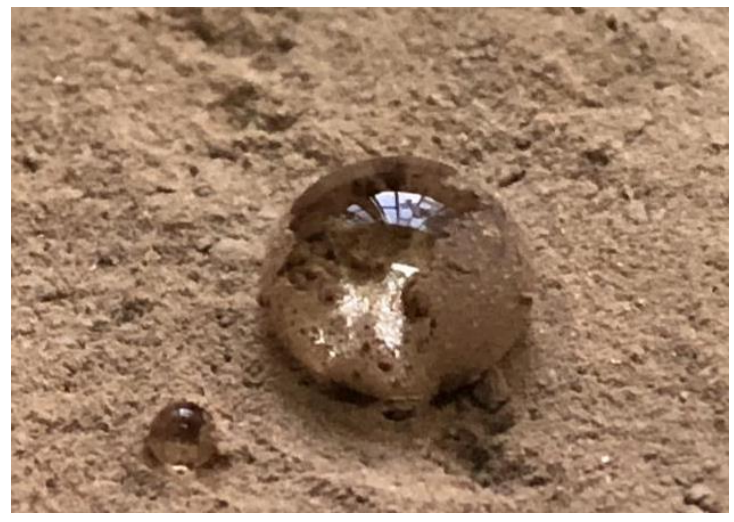

(b)

Figure 2. Water droplets on the surface of different soil samples: (a) Water droplets on the surface of Sample 0; (b) Water droplets on the surface of Sample 5.

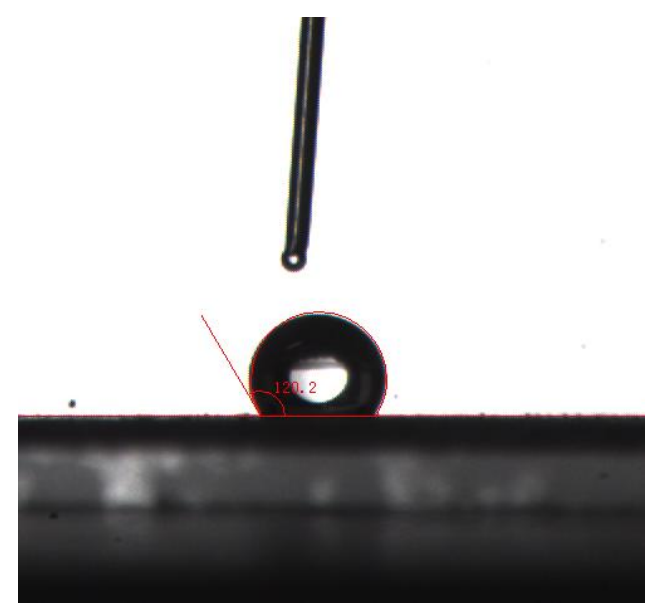

Figure 3. A contact angle image of Sample 5.

\subsection{XRD/XRF Test Results and Analysis}

Figure 4 presents the XRD diffraction pattern of Sample 0 and Sample 5, where label (1) indicates the XRD pattern of Sample 0, and label (2) indicates the XRD pattern of Sample 5. Table 2 lists the main elements tested by XRF in the different soils. 


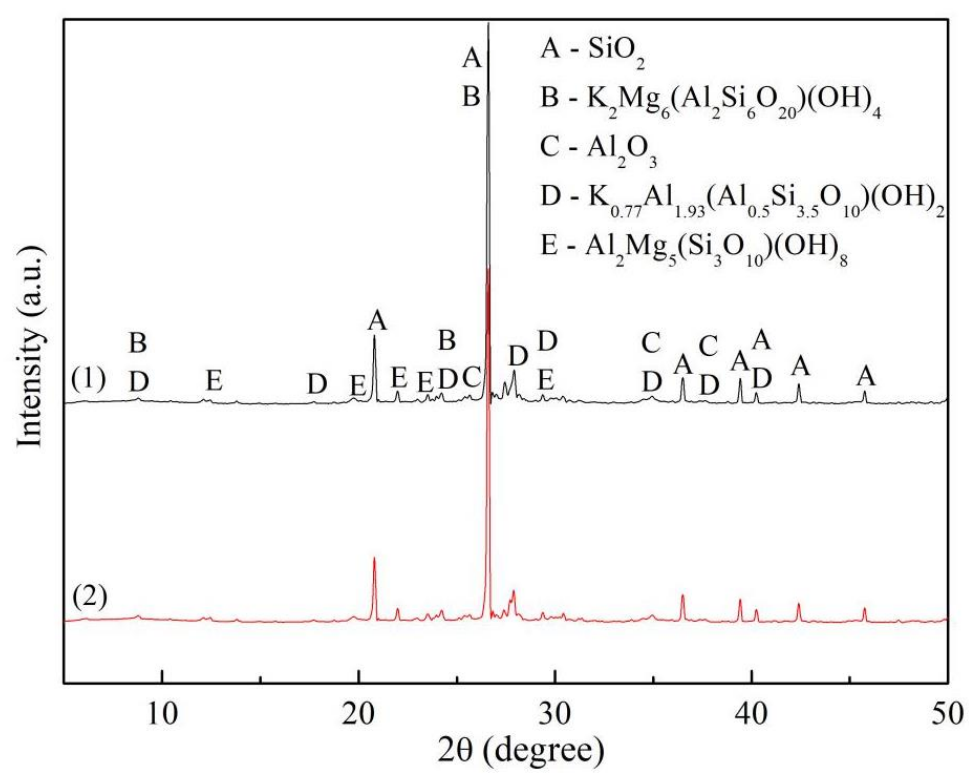

Figure 4. X-ray diffraction (XRD) diffraction patterns of different samples.

Table 2. X-ray fluorescence (XRF) results of Samples 0 and 5.

\begin{tabular}{ccccccccccc}
\hline & $\mathrm{Na}_{\mathbf{2}} \mathrm{O}$ & $\mathbf{M g O}$ & $\mathrm{Al}_{\mathbf{2}} \mathbf{O}_{\mathbf{3}}$ & $\mathrm{SiO}_{2}$ & $\mathbf{C l}$ & $\mathbf{K}_{\mathbf{2}} \mathbf{O}$ & $\mathrm{CaO}$ & $\mathrm{TiO}_{2}$ & $\mathbf{M n O}$ & $\mathrm{Fe}_{2} \mathrm{O}_{3}$ \\
\hline Sample 0 & 1.01 & 3.44 & 15.3 & 62.6 & - & 3.00 & 5.04 & 0.832 & 0.103 & 5.25 \\
Sample 5 & 2.37 & 3.40 & 15.0 & 65.7 & 0.123 & 2.81 & 4.65 & 0.769 & - & 4.72 \\
\hline
\end{tabular}

The peak curves in the figures show the following: The main crystal phase of the original soil sample is $\mathrm{SiO}_{2}, \mathrm{~K}_{2} \mathrm{Mg}_{6}\left(\mathrm{Al}_{2} \mathrm{Si}_{6} \mathrm{O}_{20}\right)(\mathrm{OH})_{4}, \mathrm{Al}_{2} \mathrm{O}_{3}, \mathrm{~K}_{0.77} \mathrm{Al}_{1.93}\left(\mathrm{Al}_{0.5} \mathrm{Si}_{3.5} \mathrm{O}_{10}\right)(\mathrm{OH})_{2}, \mathrm{Al}_{2} \mathrm{Mg}_{5}\left(\mathrm{Si}_{3} \mathrm{O}_{10}\right)(\mathrm{OH})_{8}$, which means that the soil sample is mainly composed of quartz, mica, montmorillonite, and so on. The X-ray diffraction patterns of the two samples are basically coincident, and the diffraction peaks and diffraction characteristic values only show a slight change. Combined with the results in Table 2, these results indicate that SMS added small amounts of $\mathrm{Na}$ and $\mathrm{Si}$ to the soil, which are actually $\mathrm{Na}_{2} \mathrm{CO}_{3}$ and methyl silicate.

\subsection{SEM Testing Results and Analysis}

Figures 5 and 6 present SEM images of Samples 0 and 5, respectively. By comparing the scanning electron microscopy pictures of the two, it is obvious that the contact method of soil particles changed significantly after the addition of SMS. The surface of the soil particles before adding SMS was rough, the number of pores was large, and the pore size was big. After adding SMS, the surface edges of the soil particles became relatively smooth and the pore size was greatly reduced.

According to relevant literature, SMS can be decomposed easily by weak acid. When it encounters water and carbon dioxide in the air, it will be decomposed into methyl silicic acid, and then a polymethylsiloxane membrane with waterproof properties will be quickly formed [34]. The chemical process is as follows:

$$
\begin{aligned}
& 2 \mathrm{CH}_{3} \mathrm{Si}(\mathrm{OH})_{2} \mathrm{ONa}+\mathrm{CO}_{2}+\mathrm{H}_{2} \mathrm{O} \rightarrow 2\left[\mathrm{CH}_{3} \mathrm{Si}(\mathrm{OH})_{3}\right]+\mathrm{Na}_{2} \mathrm{CO}_{3} n\left[\mathrm{CH}_{3} \mathrm{Si}(\mathrm{OH})_{3}\right] \\
& \rightarrow\left[\mathrm{CH}_{3} \mathrm{SiO}_{3 / 2}\right]_{n}+3 / 2 \mathrm{H}_{2} \mathrm{O}
\end{aligned}
$$

During the preparation of Sample 5, SMS reacted with carbon dioxide and water in the air, and the resulting waterproofing membrane evenly attached to the surface of the soil particles. On the one hand, the water repellency of the membrane makes the soil exhibit strong water repellency. On the 
other hand, the membrane adheres small particles during the stirring process, changing the way in which the soil particles are combined and narrowing the channels required for water circulation.

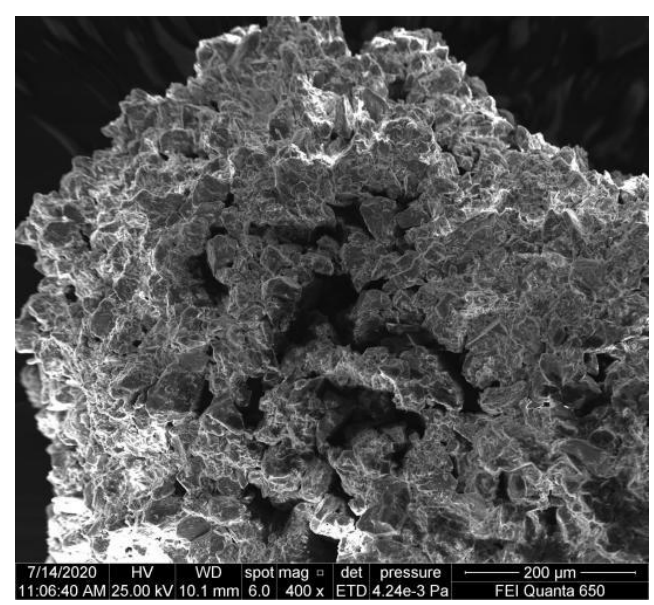

(a)

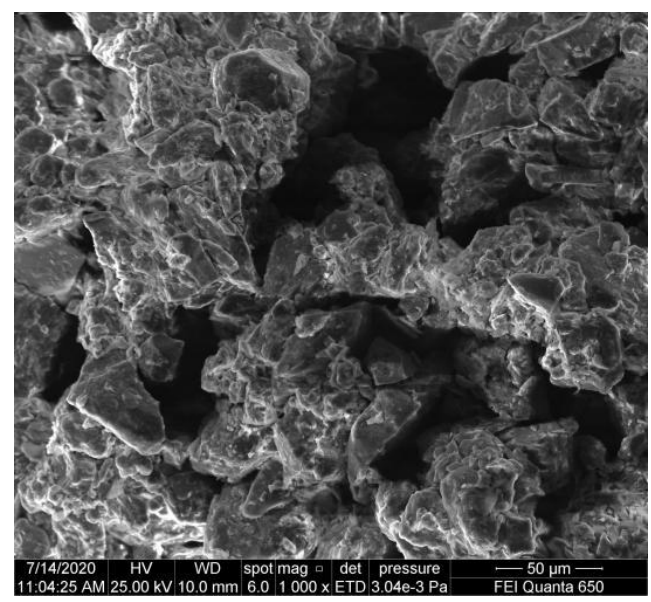

(b)

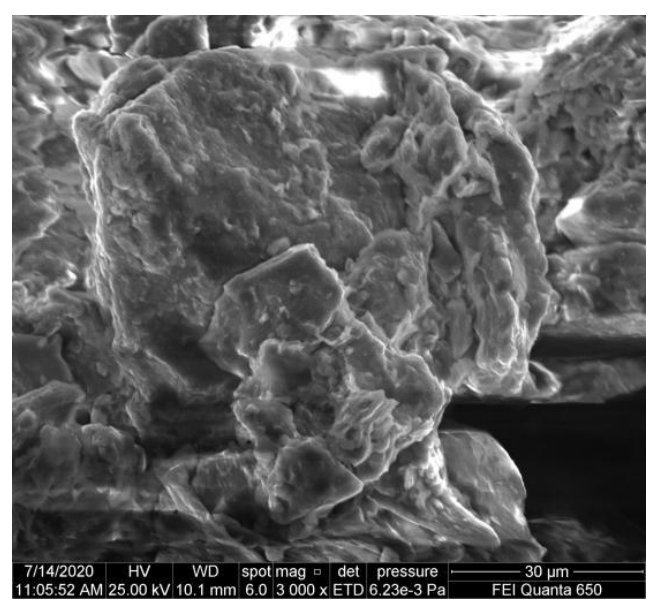

(c)

Figure 5. Micromorphology of Sample 0: (a) The magnification is 400; (b) The magnification is 1000; (c) The magnification is 3000 . 


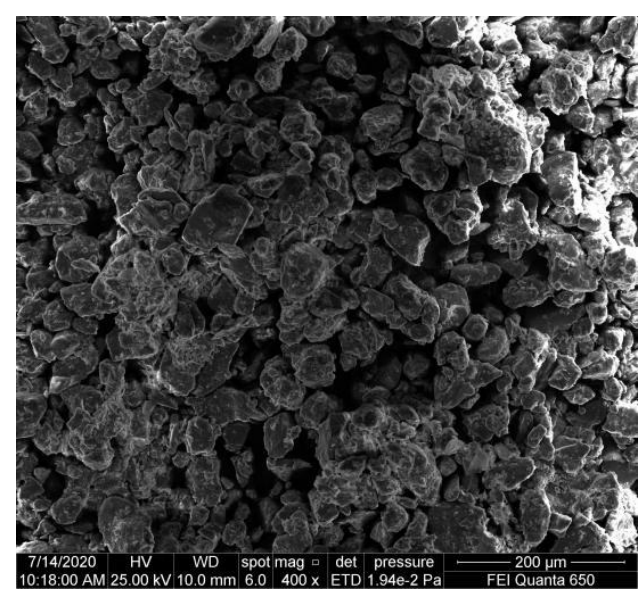

(a)

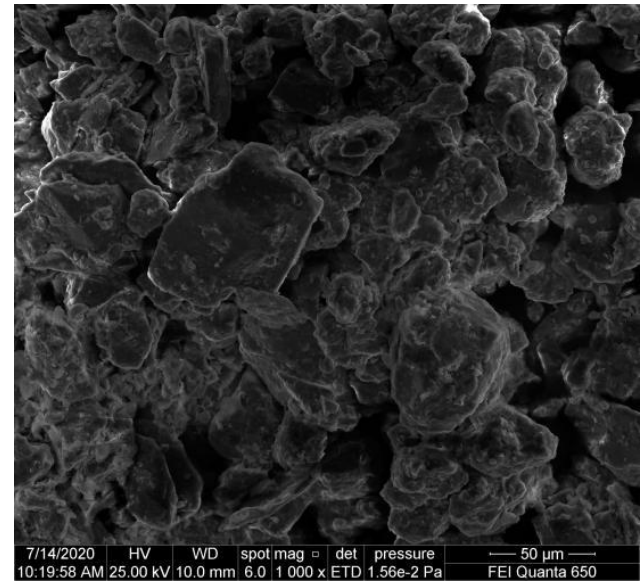

(b)

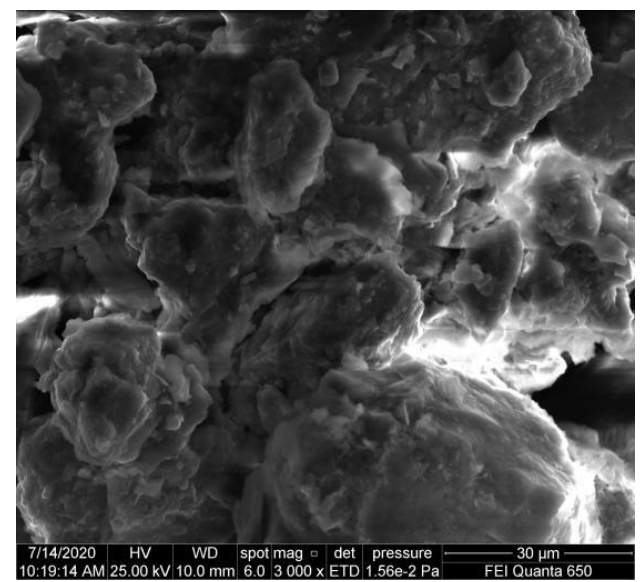

(c)

Figure 6. Micromorphology of Sample 5: (a) The magnification is 400; (b) The magnification is 1000; (c) The magnification is 3000 .

\subsection{MIP Testing Results and Analysis}

Cumulative distribution characteristics of pore volume: Mercury injection testing of Samples 0 and 5 was carried out, and the mercury intrusion-extrusion curves of the two samples are given in Figure 7. The mercury intrusion-extrusion curve reflects the changing trend of the total amount of mercury pressed into the pores as the pressure increases. It can be seen that the curves of the two samples are similar in shape, and with increasing pressure, the two cumulative mercury intrusion 
curves are characterized by a progressive relationship of "sharp rise-slow rise-sharp rise-slow rise". However, with increasing pressure, the mercury injection rate of Sample 0 was significantly lower than that of Sample 5, while when the pressure increased to $20 \mathrm{~Pa}$, the mercury injection rate of Sample 0 increased rapidly and gradually stabilized. Such a rapid change indicated that the number of pores corresponding to the pressure at this time rose substantially. The cumulative total amount of mercury intrusion of Sample 0 was slightly higher than that of Sample 5 in the end, indicating the total porosity of Sample 0 is higher than Sample 5.

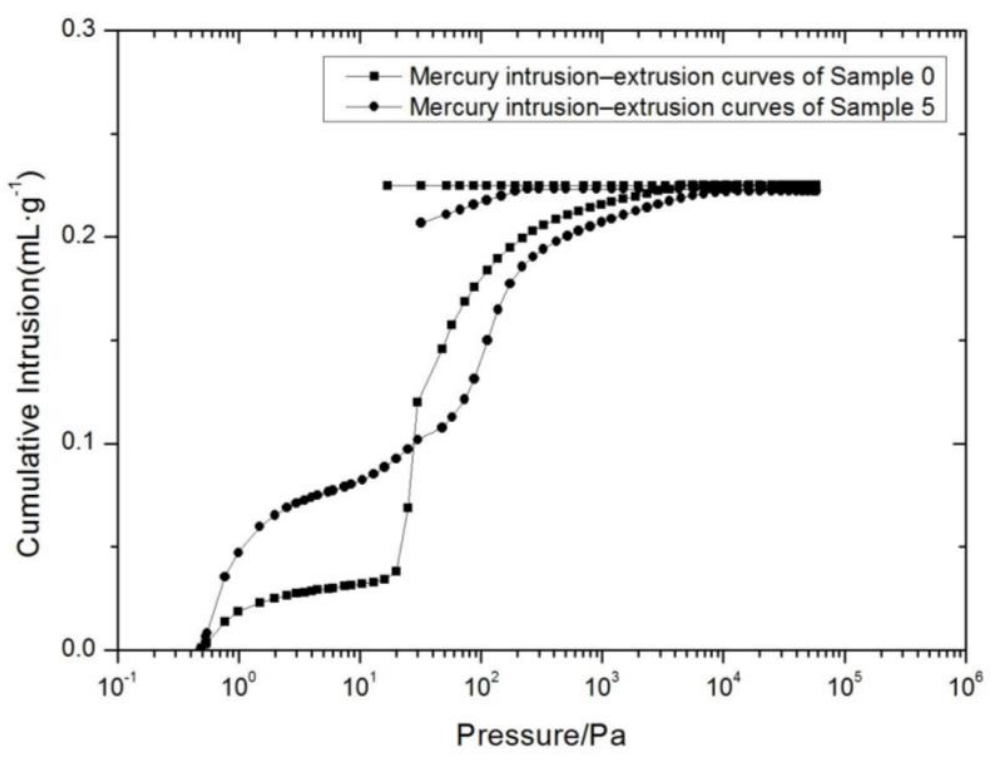

Figure 7. Mercury intrusion-extrusion curve.

Characteristics of pore distribution: during the MIP testing, the pore analysis software can automatically record the mercury intake of each level of pressure, convert them into the corresponding pore diameter, and output the pore size distribution results. After logarithmic processing of the aperture data, the relationship curve of aperture distribution density was obtained. Figure 8 shows that the proportion of small pores and medium pores in the silt was much larger than that of other pores in both soil samples. However, it can be clearly seen that the pores with a diameter of 1-10 $\mu \mathrm{m}$ of the Sample 0 have a sudden and large increase, which is consistent with the results in Figure 7 . At the same time, compared with Sample 0, the pore size distribution of Sample 5 was relatively uniform; the percentage of large pores increased, the percentage of medium pores decreased significantly, the percentage of small pores increased, and the percentage of micropores and ultrafine pores remained almost the same.

Professor Shear gives the following pore divisions [35]: large pores $(>10 \mu \mathrm{m})$, mainly intergranular pores; medium pores $(2.5-10 \mu \mathrm{m})$, mainly intraparticle pores; small pores $(0.4-2.5 \mu \mathrm{m})$, mainly intergranular and partially intragranular pores; micropore $(0.03-0.4 \mu \mathrm{m})$, belonging to intergranular pores; ultrafine pores $(<0.03 \mu \mathrm{m})$, mainly intraparticle pores.

The absorption of capillary water mainly depends on the medium pores and large pores inside the material; that is, pores with a pore diameter of more than $2.5 \mu \mathrm{m}$. Table 3 shows that the pore ratio of Sample 5 increased slightly and the specific surface area increased greatly, which indicates that the medium pores decreased and the small pores increased in number in Sample 5. This can reasonably explain the decrease of the rising height of capillary water in Sample 5. 


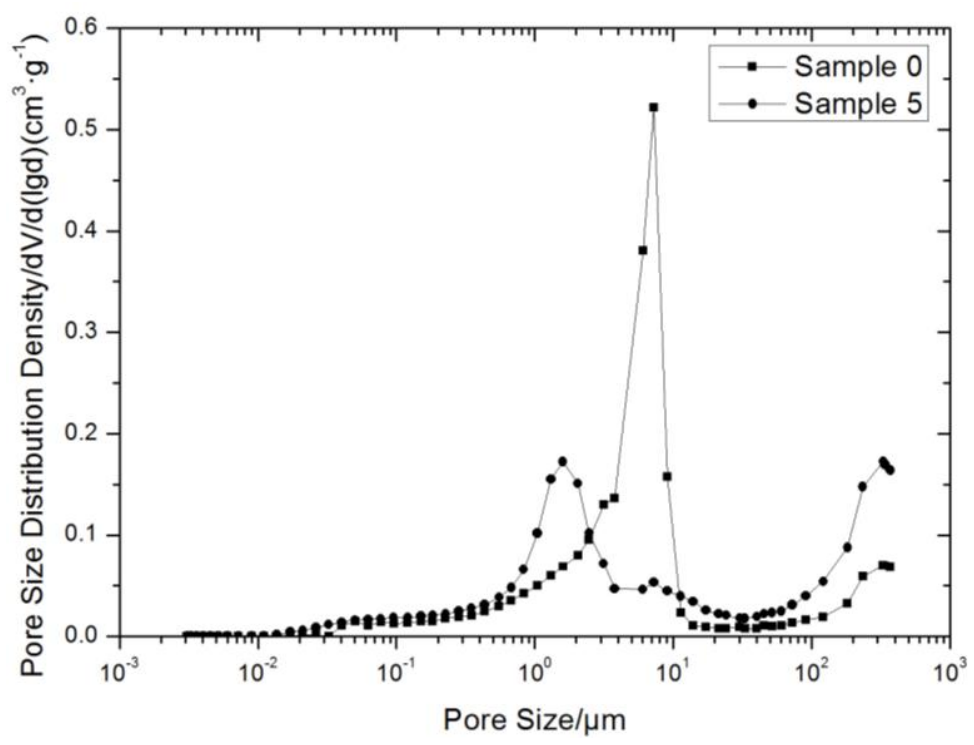

Figure 8. Density curve of pore size distribution.

Table 3. Intrusion data summary.

\begin{tabular}{cccc}
\hline & Total Intrusion Volume $(\mathbf{m L} / \mathbf{g})$ & Total Pore Area $\left(\mathbf{m}^{\mathbf{2}} \mathbf{g}\right)$ & Porosity $(\mathbf{\%})$ \\
\hline Soil sample 0 & 0.2253 & 0.878 & 33.8093 \\
Soil sample 5 & 0.2224 & 1.544 & 36.3578 \\
\hline
\end{tabular}

\section{Conclusions}

As the SMS content increased, the maximum height of capillary rise gradually decreased from $121.2 \mathrm{~cm}$ to $0 \mathrm{~cm}$, verifying the good effect of SMS in inhibiting the capillary water rise. Contact angle exceeded $120^{\circ}$, proving that the soil has good water repellency. From the combined XRD results, SEM images, and MIP results, it can be seen that after entering the soil, SMS solution was evenly dispersed with water and penetrated into the porous surfaces to form a waterproof and breathable polymethylsiloxane membrane on the surface of silty particles. The membrane had two effects on silt particles: it enclosed silt particles, and it bound adjacent silt particles together.

SMS can effectively suppress the absorption of capillary water without changing the appearance of the soil or reacting with the soil; therefore, the treatment of capillary water disease in silty sites can be achieved by using SMS added to silt as a repair material or by applying SMS solution on the site surface. The results of this study can provide an engineering basis for the treatment of capillary water disease in silty soil sites, given the insufficient existing data on the treatment of capillary water diseases.

Author Contributions: Conceptualization, Q.M.; methodology, Q.M.; validation, Q.M. and S.L.; formal analysis, Q.M. and S.L.; investigation, Q.M. and S.L.; resources, Q.M.; data curation, S.L.; writing — original draft preparation, S.L.; writing-review and editing, Q.M., and L.S; visualization, S.L.; supervision, Q.M.; project administration, Q.M.; funding acquisition, Q.M. All authors have read and agreed to the published version of the manuscript.

Funding: This research was funded by Science and Technology Development Plan of Henan Province in 2018, grant No. 182102310900.

Conflicts of Interest: The authors declare no conflict of interest.

\section{References}

1. Liu, C.H. Study on the Water Movement of Silt and the Seepage Characteristics of the City Wall Considering Clay content. Master's Thesis, Zhongyuan Institute of Technology, Henan, China, April 2019.

2. Li, L. Study on the Freeze-Thaw Cycle Effect and Micromechanism of the Strength and Disintegration of the Silt at the Site. Master's Thesis, Zhongyuan Institute of Technology, Henan, China, April 2019. 
3. Yan, C.G.; Wan, Q.; Xu, Y.; Xie, Y.; Yin, P. Experimental study of barrier effect on moisture movement and mechanical behaviors of loess soil. Eng. Geol. 2018, 240, 1-9. [CrossRef]

4. He, F.; Pan, Y.; Tan, L.; Zhang, Z.; Li, P.; Liu, J.; Song, X. Study of the water transportation characteristics of marsh saline soil in the Yellow River Delta. Sci. Total Environ. 2017, 574, 716-723. [CrossRef]

5. Zhang, Y.C.; Zhang, X.F.; Leng, Y.F. The research on stable rising height and harmful rising height of capillary water. In Proceedings of the 2011 International Conference on Transportation and Mechanical \& Electrical Engineering (TMEE), Changchun, China, 16 December 2011; pp. 2190-2197.

6. Dong, B.; Zhang, X.F.; Li, X.; Zhang, D.Q. Comprehensive test research of capillary water rising height. Chin. J. Geotech. Eng. 2008, 10, 1569-1574.

7. Spennemann, D.H.R. The creeping disaster: Dryland and urban salinity and its impact on heritage. Cult. Resour. Prot. Emerg. Prep. 2001, 24, 22-26.

8. Ren, K.B.; Wang, B.; Li, X.M.; Yin, S. Strength characteristics and pore distribution characteristics of soil ruins under the action of capillary water dry-wet cycle. Rock Soil Mech. 2019, 40, 962-970.

9. Zhu, D.Y.; Guan, Y.H. The effect of capillary water on the stability of silt subgrade. J. Shandong Univ. 2012, 42, 9398.

10. Walker, P. Terra 2003. In Proceedings of the 9th International Conference on the Study and Conservation of Earthen Architecture, Terra, Iran, 29 November 2003; GCI: Los Angeles, CA, USA, 2003.

11. Rainer, L.H. Water, wind, salt, biological, environmental, dete rioration/pathology. In Terra Literature Review; GCI: Los Angeles, CA, USA, 2003.

12. Cui, C. Disease Analysis of a City Wall Soil Site and the Stability of Modified Loess after Restoration. Master's Thesis, Xi'an University of Technology, Shanxi, China, June 2019.

13. Zhang, H.Y.; Zhu, S.B.; Li, M.; Zhang, X.C. Water repellency of monument soil treated by tung oil. Geotech. Geol. Eng. 2016, 34, 205-216. [CrossRef]

14. Yuan, Y.; Zhao, L.; Li, W.; Cao, R. Research on silty soil capillary water rising in yellow river flooded area of eastern henan. J. Highw. Transp. Res. Dev. 2016, 10, 40-46. [CrossRef]

15. Ahmed, A. Recycled bassanite for enhancing the stability of poor subgrades clay soil in road construction projects. Constr. Build. Mater. 2013, 48, 151-159. [CrossRef]

16. Ahmed, A.; Ugai, K.; Kamei, T. Investigation of recycled gypsum in conjunction with waste plastic trays for ground improvement. Constr. Build. Mater. 2011, 25, 208-217. [CrossRef]

17. Shafran, A.W.; Gross, A.; Ronen, Z.; Weisbrod, N.; Adar, E. Effects of surfactants originating from reuse of greywater on capillary rise in the soil. Water Sci. Technol. 2005, 52, 157-166. [CrossRef] [PubMed]

18. Dong, J.M.; Xu, H.Z.; Zhu, D.H.; Zhu, H. Experimental study on polymer-modified silt under different water environments. Chin. J. Geotech. Eng. 2013, 35, 1316-1322.

19. Mobbs, T.L.; Peters, R.T.; Davenport, J.R.; Evans, M.A.; Wu, J.Q. Effects of four soil surfactants on four soil-water properties in sand and silt loam. J. Soil Water Conserv. 2012, 67, 275-283. [CrossRef]

20. Abu-Zreig, M.; Rudra, R.P.; Dickinson, W.T. Effect of application of surfactants on hydraulic properties of soils. Biosyst. Eng. 2003, 84, 363-372. [CrossRef]

21. Kong, D.; Wan, R.; Chen, J.; Jing, Y.; Huang, W.; Wang, Y. The study on engineering characteristics and compression mechanisms of typical historical earthen site soil. Constr. Build. Mater. 2019, 213, 386-403. [CrossRef]

22. Han, W.C.; Li, Y.; Tan, X.F.; Guo, M.Y.; Xu, H.W. Methyl silicate inhibits clay hydration and its mechanism. Prospect. Eng. (Rock \& Soil Drill. Eng.) 2018, 45, 19-23.

23. Jiang, G.C.; Wang, J.S.; Xuan, Y. Performance evaluation and action mechanism of potassium methyl silicate shale inhibitor. Sci. Technol. Eng. 2014, 14, 6-10.

24. Yang, H.T.; Yu, J.J. Research on the influence of active components on the properties of concrete. New Build. Mater. 2019, 46, 131-133.

25. Guo, Z.; Zhu, Q.; Liu, C.; Xing, Z. Preparation of Ca-Al-Fe deicing salt and modified with sodium methyl silicate for reducing the influence of concrete structure. Constr. Build. Mater. 2018, 172, 263-271. [CrossRef]

26. Liu, G. Experimental Study on Adding Chloride Ion Transmission Blocking Materials to Cement Concrete. Master's Thesis, Chang'an University, Shanxi, China, May 2017.

27. Li, X.J. Microwave Hardened Water Glass Sand Composite Hardening Process and Anti-Hygroscopicity. Master's Thesis, Huazhong University of Science and Technology, Hubei, China, January 2013. 
28. Wang, H.F. Key Technical Foundations of Microwave Hardened Water Glass Sand Application. Ph.D. Thesis, Huazhong University of Science and Technology, Hubei, China, January 2012.

29. Yuan, Y.Q.; Jia, M.; Li, W. Experimental study of yellow silty soil stabilized by sodium methyl silicate. China Sci. Technol. Pap. 2017, 12, 831-844.

30. JTGE40-2007. Highway Geotechnical Test Regulations [S]; People's Communications Press: Beijing, China, 2007.

31. Zhang, W.P.; Sun, Y.F.; Tong, W.W.; Song, Y.P.; Dong, L.F.; Liu, X.Y. An analytical method for studying the distribution characteristics of soil particles and pores based on sem images. Adv. Mar. Sci. 2018, 36, 605-613.

32. Liu, Y.J.; Wu, J.S.H.; Xie, Z.H. Experimental study on microstructure characteristics of soft soil based on NMR and SEM. J. Guangdong Univ. Technol. 2018, 35, 49-56.

33. Wu, S.; Yang, J.; Yang, R.; Zhu, J.; Liu, S.; Wang, C. Investigation of microscopic air void structure of anti-freezing asphalt pavement with X-ray CT and MIP. Constr. Build. Mater. 2018, 178, 473-483. [CrossRef]

34. Lu, F.; Nie, J.T. Application research of sodium methyl silicate (organic silicone water repellent). Jiangxi Chem. Ind. 1995, 2, 31-34.

35. Shear, D.L.; Olsen, H.W.; Nelson, K.R. Effects of desiccation on the hydraulic conductivity versus void ratio relationship for a natural clay. In Transportation Research Record; National Academy Press: Washington, DC, USA, 1993; pp. 1365-1370.

(C) 2020 by the authors. Licensee MDPI, Basel, Switzerland. This article is an open access article distributed under the terms and conditions of the Creative Commons Attribution (CC BY) license (http://creativecommons.org/licenses/by/4.0/). 